\title{
Role of Peroxisome Proliferator-Activated Receptor Alpha in the Control of Cyclooxygenase 2 and Vascular Endothelial Growth Factor: Involvement in Tumor Growth
}

\author{
Raquel Grau, Manuel D. Díaz-Muñoz, Cristina Cacheiro-Llaguno, Manuel Fresno, and Miguel A. Iñiguez \\ Departamento de Biología Molecular, Centro de Biología Molecular "Severo Ochoa" UAM-CSIC, \\ Universidad Autónoma de Madrid, 28049 Madrid, Spain
}

Correspondence should be addressed to Miguel A. Iñiguez, mainiguez@cbm.uam.es

Received 11 March 2008; Revised 20 June 2008; Accepted 24 June 2008

Recommended by Dipak Panigrahy

A growing body of evidence indicates that PPAR (peroxisome proliferator-activated receptor) $\alpha$ agonists might have therapeutic usefulness in antitumoral therapy by decreasing abnormal cell growth, and reducing tumoral angiogenesis. Most of the antiinflammatory and antineoplastic properties of PPAR ligands are due to their inhibitory effects on transcription of a variety of genes involved in inflammation, cell growth and angiogenesis. Cyclooxygenase (COX)-2 and vascular endothelial growth factor (VEGF) are crucial agents in inflammatory and angiogenic processes. They also have been significantly associated to cell proliferation, tumor growth, and metastasis, promoting tumor-associated angiogenesis. Aberrant expression of VEGF and COX-2 has been observed in a variety of tumors, pointing to these proteins as important therapeutic targets in the treatment of pathological angiogenesis and tumor growth. This review summarizes the current understanding of the role of PPAR $\alpha$ and its ligands in the regulation of COX-2 and VEGF gene expression in the context of tumor progression.

Copyright (C) 2008 Raquel Grau et al. This is an open access article distributed under the Creative Commons Attribution License, which permits unrestricted use, distribution, and reproduction in any medium, provided the original work is properly cited.

\section{INTRODUCTION}

Peroxisome proliferator-activated receptors (PPARs) are members of the nuclear receptor family of transcription factors. They modulate gene transcription in response to specific ligands by binding as heterodimers with the retinoid $\mathrm{X}$ receptor (RXR) to a specific peroxisome proliferatorresponse element (PPREs) on target genes (reviewed in [1, 2]). Three distinct isoforms of PPARs have been described PPAR $\alpha, \beta / \delta$, and $\gamma$, each encoded by a different gene and showing a distinct tissue distribution [3]. Originally found to be involved in the regulation of lipid and glucose metabolism, $[4,5]$ interest in these receptors has increased dramatically as a consequence of recent studies showing their involvement in tumoral cell growth and inflammation (reviewed in [6-9]). Therefore, in addition to their wellknown effects in diabetes and hyperlipidemic disorders, pharmacological agents that target PPARs may have therapeutic applications in inflammatory diseases and cancer.

PPAR $\alpha$ was the first PPAR identified [10]. It has a wide tissue distribution being expressed in liver, skeletal muscle, intestine, kidney, adipose tissue, and vascular endothelial cells, tissues in which fatty acids are predominantly catabolized $[11,12]$. Several ligands have been shown to bind PPAR $\alpha$ and to regulate transcriptional activity of target genes involved in the regulation of fatty acid metabolism as fatty acid transporters, catabolic enzymes involved in mitochondrial, and peroxisomal oxidation as well as genes necessary for the maintenance of redox balance during the oxidative catabolism of fatty acids $[4,5,13]$. PPAR $\alpha$-activating ligands include a number of pharmacological compounds as well as fatty acid and fatty acid-derived molecules (reviewed in [2]). Lipid-lowering fibrates as Bezafibrate, Clofibrate, Fenofibrate and Gemfibrozil as well as certain nonsteroidal anti-inflammatory drugs (NSAIDs) bind and activate PPAR $\alpha$ $[14,15]$. In addition, a variety of unsaturated and saturated fatty acids including arachidonic acid, palmitic acid, linoleic acid, linolenic acid, and oleic acid can act as natural ligands of PPAR $\alpha$ as they can bind and activate this receptor. Some eicosanoids derived from the metabolism of arachidonic acid such as leukotrienes (LTs), hydroxyeicosatetraenoic acids (HETEs), and prostaglandins (PGs) can also be effective 
ligand agonists for specific PPAR isoforms [16-19]. However, it is not clear whether the concentrations at which binding of these compounds occurs are physiologically relevant.

In addition to its known role in the regulation of genes involved in fatty acid metabolism, this isoform has been shown to attenuate the inflammatory response $[6,7,9]$. Most recently, an antitumoral role of PPAR $\alpha$ and its ligands has been proposed $[7,8]$. This assumption is supported by recent experimental evidence, revealing antitumoral and anti-angiogenic properties of PPAR $\alpha$ activators both in vitro and in vivo.

\section{ANTI-INFLAMMATORY ACTIONS OF PPAR $\alpha$}

In recent years, considerable attention has focused on the involvement of PPARs in inflammatory processes. Antiinflammatory effects of PPAR ligands, in particular those of PPAR $\alpha$ and PPAR $\gamma$, have been ascribed to inhibition of the expression of inflammatory genes and negative interference with pro inflammatory transcription factor signaling pathways in vascular and inflammatory cells (reviewed in $[1,6,20]$. The first evidence for the involvement of PPAR $\alpha$ in the control of inflammation came from the studies of the inflammatory response elicited by LTB4 in PPAR $\alpha$ deficient mice. In these animals, inflammatory response to LTB4 was prolonged compared to WT mice, correlating with the ability of LTB4 to activate PPAR $\alpha$ and regulate the expression of genes involved in its own catabolism [21]. Thus, proinflammatory lipid metabolites may serve as ligands for PPARs thereby activating PPAR $\alpha$ responsive enzymes responsible for their clearance. Therefore, some of the antiinflammatory actions of these receptors can occur through this autoregulatory loop in lipid homeostasis. Several lipids mediators, as the polyunsaturated fatty acids (PUFAs), can function as ligands for PPARs [2]. Arachidonic acid is a precursor of several eicosanoids that have pro inflammatory properties whereas the $\omega-3$ PUFAs are precursors of antiinflammatory eicosanoids as EPA (eicosapentanoid acid) and docosahexaenoic acid (DHA). These $\omega$-3 PUFAs derivatives have been reported to decrease the production of several pro inflammatory cytokines, having beneficial effects in several inflammatory diseases as rheumatoid arthritis and inflammatory bowel disease $[22,23]$.

Several studies have confirmed the anti-inflammatory properties of PPARs in vitro and in vivo through the regulation of genes involved in the inflammatory response. PPAR agonists decrease plasma concentrations of interleukin (IL)6 , tumor necrosis factor (TNF) $\alpha$, and interferon (IFN)- $\gamma$ in humans $[24,25]$. In vascular smooth-muscle cells, PPAR $\alpha$ ligands inhibit IL-1-induced production of IL-6, COX-2, and prostaglandins [25]. PPAR $\alpha$ activation inhibits cytokineinduced expression of vascular cell-adhesion molecule-1 (VCAM-1) and vascular endothelial growth factor receptor2 (VEGFR-2) in endothelial cells $[26,27]$. PPAR $\alpha$ have been also involved in the downregulation of the production of IL-2 and TNF $\alpha$ by T lymphocytes [28].

At the molecular level, most of the inhibitory actions of PPAR $\alpha$ on gene transcription result from its ability to transrepress the activities of many activated transcription factors such as nuclear factor $(\mathrm{NF})-\kappa \mathrm{B}[25,29]$, activator protein1 (AP-1) $[29,30]$ C/EBP $\beta[31,32]$, signal transducers and activators of transcription (STATs) [33], and transcription factor specificity protein 1 (Sp-1) [27]. Negative regulation of gene expression by PPAR $\alpha$ can occur by several mechanisms (Figure 1). Activated PPAR-RXR complexes may compete for limited amounts of essential coactivators shared with other transcription factors. Direct physical interactions between PPARs and specific transcription factors have been also proposed to mediate transcriptional inhibition by activated $\operatorname{PPAR} \alpha$, resulting in reduced binding to their cognate response elements. Agonists-activated PPAR $\alpha$ can effectively antagonize NF- $\kappa \mathrm{B}$ and $\mathrm{AP}-1$-mediated signaling pathways in a bidirectional manner by physical interaction with the Rel homology domain of NF $\kappa \mathrm{B}-\mathrm{p} 65$ and with the aminoterminal of c-Jun, respectively [34]. Physical association of the Cterminal DNA binding region of $\mathrm{c} / \mathrm{EBP} \beta$ with PPAR $\alpha$ mediates inhibition of alpha1-acid glycoprotein gene expression [31]. PPAR $\alpha$ agonists can also influence transcriptional activation by modulating the expression of transcriptional repressors such as $\mathrm{I} \kappa \mathrm{B} \alpha$ (Kleemann, 2003 \#1223; Vanden Berghe, $2003 \# 2170$ \}). Finally, an additional mechanism of transrepression relies on the ability of some PPAR $\alpha$ ligands to interfere with the activation of certain members of the mitogen-activated protein kinase (MAPK) cascade as Jun kinase (JNK) and p38 MAPK [30, 35, 36].

\section{INVOLVEMENT OF PPAR $\alpha$ IN CANCER}

Rapidly accumulating evidence links members of the PPAR family and their agonists to cellular growth and tumor progression. The role of the PPAR $\gamma$ isotype in cancer has been widely studied with a large number of reports demonstrating antitumoral properties of PPAR $\gamma$ agonists in a variety of different malignancies [8]. Concerning to the involvement of the PPAR $\alpha$ form and its ligands in cancer, both tumor promotion and suppression properties have been reported [37]. Sustained PPAR $\alpha$ activation by agonists as clofibrate and $\mathrm{Wy}-14643$ induce hepatocarcinogenesis in rodents $[38,39]$. However, epidemiological data on long-term administration of PPAR $\alpha$ activators in the clinic discard the occurrence of these effects in human [40-43]. Discrepancies on the effects of PPAR $\alpha$ ligands in rodents and human liver seem to be due to several differences between species [44]. PPAR $\alpha$ mediated signaling is less efficient in human than in mice $[37,43,45]$ and expression of this receptor is 10 to 20 times higher in rodent hepatocytes compared to human liver [46].

Emerging evidence indicates that PPAR $\alpha$ ligands are able to suppress the growth of different types of human carcinomas. PPAR $\alpha$ is expressed in a variety of human and murine tumor cell lines [47-49]. Expression of PPAR $\alpha$ have been also reported in clinical samples of several types of human cancers as colorectal carcinoma [50], prostate adenocarcinoma, [47, 51], testicular cancer [52], bladder carcinoma [53], and medulloblastoma [54]. PPAR $\alpha$ ligands are able to arrest the growth of human cancer cell lines in vitro and to slow the growth of transplanted human tumor cells in nude mice. These anticancer effects have been 


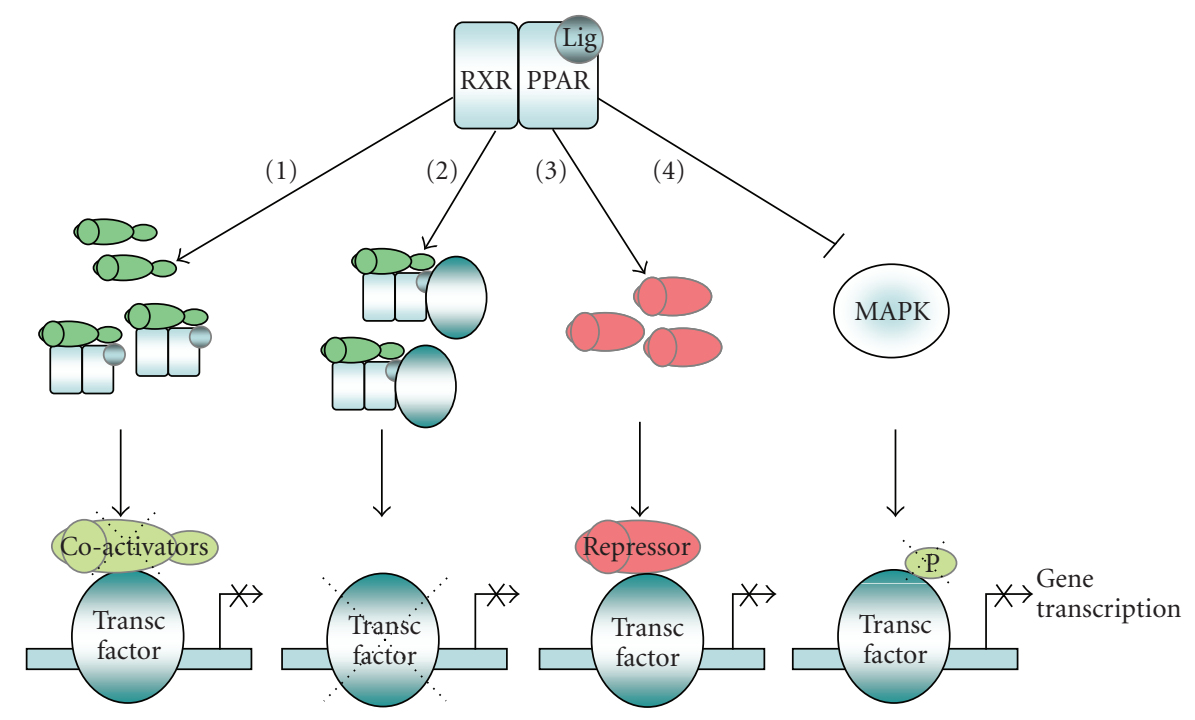

FIGURE 1: Negative regulation of gene expression by PPARs. Different mechanisms of transrepression through interference of activated PPARs with activation of transcription factors have been described. (1) Activated PPAR-RXR complexes may sequester essential coactivators shared with other transcription factors. (2) Physical association of PPARs with specific transcription factors results in reduced binding to their cognate response elements. (3) PPAR $\alpha$ agonists can also influence transcriptional activation by upregulating the expression of transcriptional repressors such as $\mathrm{I} \kappa \mathrm{B} \alpha$. (4) PPAR $\alpha$-mediated interference on the activation of members of the mitogen-activated protein kinase (MAPK) cascade influences transcription factor activation.

observed in several different cancer cell types including hepatoma [55], melanoma [56], glioblastoma and fibrosarcoma [49], endometrial and ovarian cancer [57-59], as well as colon carcinoma $[50,60,61]$. Clofibric acid, a ligand for $\operatorname{PPAR} \alpha$ inhibits growth of ovarian cancer both in vivo and in vitro $[58,59]$. Mice treated topically with the PPAR $\alpha$ ligand Wy-14643 exhibited diminished skin tumorigenesis [62]. Moreover, Fenofibrate suppresses the metastatic potential of melanoma cells $[56,63]$.

Even though accumulative evidence shows data suggesting that PPAR $\alpha$ ligands may display antitumoral properties, the precise mechanism remains unclear. A number of reports suggest that antitumor properties of PPAR $\alpha$ activators reside on their anti-inflammatory and anti-angiogenic effects [27, 64, 65] (Figure 2). The dependence on the presence of PPAR $\alpha$ for the antitumorigenic and anti-angiogenic role of PPAR ligands has been determined by the analysis of their effects in PPAR $\alpha$ null mice. Wy-14643-mediated antitumoral and anti-angiogenic responses on tumor and endothelial cells are absent in PPAR $\alpha$ KO mice [66]. Panigrahy and coworkers [49] have shown the importance of the microenvironment in tumor progression in such a way that the activation of PPAR $\alpha$ expressed in endothelial and inflammatory cells of the host rather than in the tumoral cells is critical for anti-inflammatory, antitumor and anti-angiogenic activity of PPAR $\alpha$ agonists. Consistent with the anti-inflammatory role of this receptor, PPAR $\alpha$ null mice exhibit an increase of inflammatory infiltrates in tumors. Paradoxically, in spite of the enhanced inflammatory response in the absence of $\operatorname{PPAR} \alpha$, tumor growth is suppressed in these animals as a consequence of an increased production of anti-angiogenic factors TSP-1 and endostatin [67]. The immune system can have a multitude of effects on cancer development and progression, both favorable and detrimental $[68,69]$. This apparent contradiction has been explained by the severity and duration of the inflammatory response associated to tumor growth. While acute inflammation is part of the defense response that may participate in the remission of preclinical cancers, chronic inflammation can promote tumor development with infiltrating innate immune cells providing proinflammatory and proangiogenic factors including cytokines, chemokines, VEGF, and prostanoids [70-72]. The association between cancer and inflammation has been also illustrated by epidemiological studies showing that the use of anti-inflammatory compounds in chronic inflammatory diseases reduces cancer risk tumor $[73,74]$. In this sense, $\operatorname{PPAR} \alpha$-mediated anti-inflammatory actions can be responsible for their potential chemopreventive effects in tumor progression.

An emerging area of interest is the association of antiinflammatory actions of dietary PUFAs as potential natural agonists of PPARs with cancer risk. Increasing evidence suggests that dietary fat regulation of gene expression can play a critical role in initiation and progression of human cancer and epidemiological studies have suggested an association between dietary fat and cancer risk [75, 76]. A number of reports have shown the beneficial effects of consumption of $\omega$-3 PUFAs, associated with anti-inflammatory effects and with protection against primary tumor development $[22,23,75]$. Although some of the effects of dietary lipids can be linked to PPARs-mediated signaling, additional research is needed to understand the potential connection between dietary fat intake and PPARs in the control of inflammation and tumor progression. 


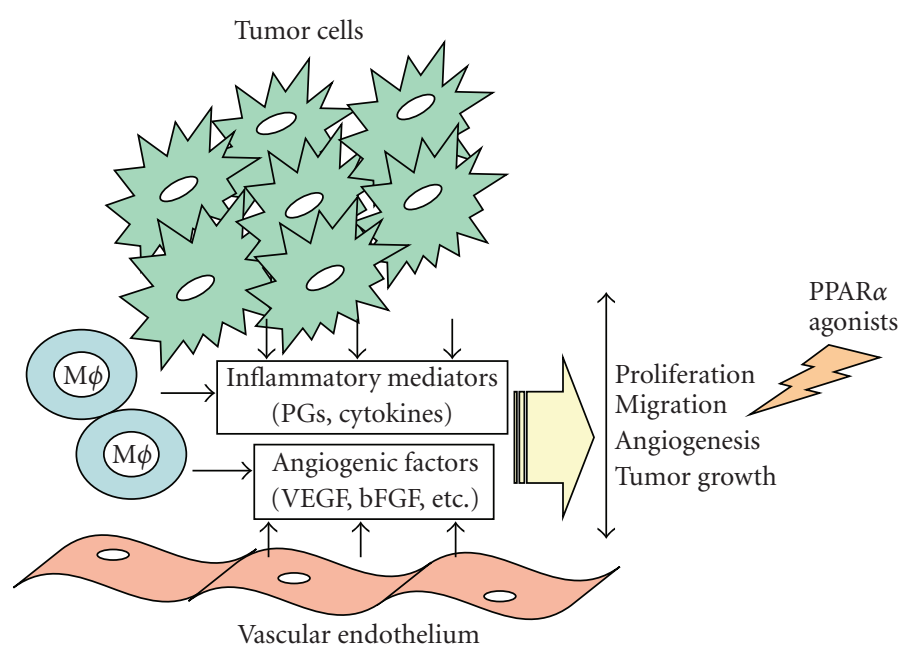

FIGURE 2: Antitumoral effects of PPAR $\alpha$ ligands. Tumor progression depends on a cascade of cellular signals involving: (a) proinflammatory factors (cytokines, COX-2 derived prostaglandins (PGs), chemokines); (b) proangiogenic factors (VEGF, bFGF, and PGs) produced by endothelial and inflammatory cells, stromal fibroblasts, and tumor cells. These factors promote cell proliferation, migration, and induce new vessels that deliver nutrients and oxygen to the malignant cells and therefore allow tumor growth and metastasis. PPAR $\alpha$ ligands may display antitumoral properties by their inhibitory effects on the transcription of genes involved in inflammation, cell growth, and angiogenesis thus leading to the inhibition of tumor growth.

TABLE 1: Effects of PPAR $\alpha$ ligands on COX-2 signaling.

\begin{tabular}{|c|c|c|}
\hline PPAR $\alpha$ ligand & Action/effect & References \\
\hline \multicolumn{3}{|l|}{ Wy-14643 } \\
\hline & Inhibition of IL-1-induced COX-2 expression in vascular smooth muscle cells & [25] \\
\hline & Inhibition of LPS-induced COX-2 expression in THP-1 monocytes & {$[94]$} \\
\hline & Inhibition of TPA-induced COX-2 expression in colon carcinoma cell lines & {$[30]$} \\
\hline & Inhibition of COX-2 expression in B16-F10 melanoma tumor & [49] \\
\hline & Inhibition of COX-2 up regulation by experimental steatohepatitis in liver & [95] \\
\hline \multicolumn{3}{|l|}{ Fenofibrate } \\
\hline & Inhibition of COX-2 expression in B16-F10 melanoma tumor & [49] \\
\hline & Inhibition of b-FGF induced COX-2 expression in endothelial cells & [65] \\
\hline \multicolumn{3}{|l|}{ Clofibric acid } \\
\hline & Inhibition of COX-2 expression in tumor xenografts & {$[58]$} \\
\hline & Inhibition of mPGES-1 expression in tumor xenografts & [59] \\
\hline
\end{tabular}

\section{4. $\operatorname{PPAR} \alpha$, COX-2, AND CANCER}

\subsection{COX-2: an essential role in inflammation and tumor growth}

Cyclooxygenases (COX-1 and COX-2) convert arachidonic acid to prostaglandin $\mathrm{H}_{2}\left(\mathrm{PGH}_{2}\right)$, an endoperoxide intermediate that, via specific synthases, is then transformed to prostaglandins $\left(\mathrm{PGE}_{2}, \mathrm{PGD}_{2}, \mathrm{PGF}_{2 \alpha}, \mathrm{PGI}_{2}\right)$ and thromboxanes $\left(\mathrm{TXA}_{2}\right)$. Whereas COX-1 is constitutively expressed in most tissues, COX-2 is transcriptionally upregulated in response to mitogens, tumor promoters, and pro inflammatory stimuli in a discrete number of cell types (reviewed in [77-79]). These enzymes are the target of nonsteroidal antiinflammatory drugs (NSAIDs), one of the most widely used therapeutic for the relief of pain and inflammation (reviewed in [80-82]). The anti-inflammatory and analgesic efficacy of drugs arises essentially from inhibition of the enzymatic activity of COXs. As COX-2 is though to be the predominant isoform involved in the inflammatory response, the ability of NSAIDs to inhibit COX-2 activity may explain their therapeutic effects as anti-inflammatory drugs. Therefore, most of the new research on anti-inflammatory drugs has been aiming at targeting the COX-2 inducible production of PGs.

In addition to its essential role in inflammation, accumulating evidence links COX-2 with cancer and angiogenesis, suggesting that drugs that target COX-2 and related signaling cascades could be used as antitumoral agents [74]. Many human cancers display elevated COX-2 expression and studies in COX-2 null mice have demonstrated the role of this enzyme in tumor progression and metastasis [83-85]. 
TABLE 2: Effects of PPAR $\alpha$ ligands on VEGF signaling.

\begin{tabular}{|c|c|c|}
\hline PPAR $\alpha$ ligand & Action/effect & References \\
\hline \multicolumn{3}{|l|}{ Wy-14643 } \\
\hline & Inhibition of VEGF-mediated endothelial cell migration & {$[27,49,64]$} \\
\hline & Inhibition of VEGF production by glioblastoma U87 cells & {$[49]$} \\
\hline & Inhibition of VEGF-induced phosphorylation of Akt & {$[64]$} \\
\hline & Inhibition of VEGF-mediated angiogenesis in vitro & [27] \\
\hline \multicolumn{3}{|l|}{ Fenofibrate } \\
\hline & Inhibition of VEGF production by glioblastoma U87 cells & [49] \\
\hline & Reduction of plasma VEGF & {$[96]$} \\
\hline & Inhibition of VEGF-induced phosphorylation of Akt & {$[64]$} \\
\hline & Inhibition of VEGFR2 expression in endothelial cells & [27] \\
\hline \multicolumn{3}{|l|}{ Clofibric acid } \\
\hline & Inhibition of VEGF expression in tumor xenografts & {$[58]$} \\
\hline
\end{tabular}

Moreover, epidemiological studies have revealed a role of selective COX-2 inhibitors in decreasing the risk of developing colon cancer and in suppressing tumor formation and growth in animal models [73, 86-88]. COX-2 inhibitors can block both the production of angiogenic factors and the migration of vascular endothelial cells, and thus decrease tumor growth $[89,90]$. Although some of the effects of these drugs on tumor regression might result from modulation of COX-2-independent pathways [91], it is likely that COX-2 is an important mediator of tumor growth.

\subsection{Effects of PPAR $\alpha$ ligands on COX-2 expression}

The activity of COX-2 is closely linked to PPARs as COX-2 catalyzes the production of fatty acid derivates as prostanoids that are PPAR activators [2]. Modulation of COX-2 activity should influence the local availability of PPAR ligands; therefore, indirectly modulating PPAR activity. Moreover, some NSAIDs may act as $\operatorname{PPAR} \alpha$ and $\gamma$ ligands, suggesting that, in addition to inhibit prostaglandin production, they might regulate gene expression as part of their anti-inflammatory and chemopreventive mechanisms [92, 93]. Downregulation of COX-2 expression by PPAR $\alpha$ ligands may account for some of the anti-inflammatory, anti-angiogenic and antitumoral properties of these drugs in a variety of cell types [20] (Table 1). PPAR $\alpha$ agonists as Wy-14643 inhibit macrophage differentiation and COX2 gene expression [94]. In liver, COX-2 upregulation upon experimental nutritional steatohepatitis is suppressed by the $\operatorname{PPAR} \alpha$ agonist Wy-14,643 in wt but not in PPAR $\alpha \mathrm{KO}$ mice. This effect has been ascribed to the ability of activated $\operatorname{PPAR} \alpha$ to interfere with the NF- $\kappa \mathrm{B}$-signaling pathway [95]. Transcriptional interference of activated PPAR $\alpha$ with NF$\kappa \mathrm{B}$ also explains the inhibition of COX-2 induction and PG production in response to IL-1 in vascular smooth muscle cells [25]. The NF- $\kappa \mathrm{B}$ target genes VCAM-1 and COX-2 are also downregulated by $\operatorname{PPAR} \alpha$ ligands in response to cytokine activation [29]. Regarding to experimental support for anti-angiogenic and antitumoral actions of these drugs related to their effects on COX-2 expression, it has been shown that Fenofibrate inhibits bFGF-mediated angiogenesis and COX-2 mRNA expression in endothelial cells [65]. Panigrahy and cols have observed suppression of COX-2 expression in Fenofibrate and Wy-14643 treated tumors [49]. Clofibric acid suppresses the growth of tumor xenograts of ovarian cancer cell lines with decreased microvessel density, $\mathrm{PGE}_{2}$ production, and COX-2 and mPGES-1 expression $[58,59]$. Diminished expression of COX-2 upon PPAR $\alpha$ agonist treatment was parallel with reduced expression of AP-1. Similarly, in colon carcinoma cells, PPAR $\alpha$ agonists severely diminish phorbol ester-mediated AP-1-dependent induction of COX-2 expression [30].

\section{PPAR $\alpha$, VEGF, AND CANCER}

\subsection{VEGF: a therapeutic target in tumoral angiogenesis}

Angiogenesis, defined as the formation of new blood vessels from preexisting vasculature, occurs under physiological conditions during embryonic development and is required for wound healing and reproduction in the adult. Indispensable for physiological processes, angiogenesis is highly regulated via fine tuning of the balance between pro- and anti-angiogenic factors [97]. Excessive angiogenesis is tightly linked to human disease, including chronic inflammatory disease, diabetic retinopathy, and cancer [98, 99]. Ample evidence shows that blockade of tumoral angiogenesis often relieves the severity of cancer [100].

Both cancer cells and cells attracted to the sites of inflammation are able to produce proangiogenic factors that cause endothelial cell recruitment and proliferation for the supply of oxygen and nutrients that favor the growth of solid tumors and facilitate metastasis. In this context, tumor-associated hypoxia plays an essential role in the regulation of angiogenesis [101]. Response to hypoxia is mediated by members of the hypoxia-inducible transcription factors (HIFs) involved in the regulation of the expression of genes participating in oxygen homeostasis [102, 103]. In addition, hypoxia has been also found to drive induction 
of potent angiogenic and inflammatory factors including VEGF, VEGF-R1 and -R2, angiotensin, metalloproteinases, and COX-2 [104-106]. This response of tumors to hypoxia contributes to the malignant phenotype and to more aggressive tumor progression [107].

It has been well established that VEGF signaling pathway is one of the key regulators in angiogenesis [108, 109]. Cytokines, growth factors, tumor promoters, and hypoxia modulate the expression of VEGF [110, 111]. Activated VEGF may bind to two types of tyrosine kinases receptors: VEGFR-1 and VEGFR-2. Proangiogenic actions of VEGF as vascular endothelial cell permeability, proliferation migration, and survival are mediated mainly through binding an activation of the VEGFR-2 [112, 113]. Accumulating evidence supports a key role of VEGF in cancer, contributing to tumor neovascularization and dissemination. Increased expression of this factor has been found in most tumors, and agents neutralizing VEGF expression or activity inhibit tumor growth in vivo (reviewed in $[99,100,114]$ ).

\subsection{Inhibition of VEGF signaling by PPAR $\alpha$ agonists}

$\operatorname{PPAR} \alpha$ ligands can inhibit endothelial cell proliferation and migration and induce endothelial cell apoptosis in vitro, suggesting an important role of this receptor in tumor angiogenesis. Part of these effects occurs through the ability of PPAR $\alpha$ ligands to interfere with VEGF-mediated signaling. (Table 2). At the transcriptional level, PPAR agonists have been shown to inhibit endothelial VEGFR-2 expression by repressing transactivation and binding of Sp1 to DNA [27]. Wy-14643 downregulates TPA-mediated transcriptional induction of VEGF by interference with activation of AP-1 [30]. Interestingly, lipid-lowering therapy with Fenofibrate induces a significant reduction of VEGF levels in serum [96]. Anti-angiogenic actions of PPAR $\alpha$ agonists may explain some of their antitumoral effects. Fenofibrate reduces adventitial angiogenesis and inflammation in a porcine model of coronary angioplasty [115]. Both Fenofibrate and $\mathrm{Wy}-14643$ are able to suppress VEGF secretion in glioblastoma cells and Lewis lung carcinoma cells and to inhibit angiogenesis both in vivo and in vitro [49]. Moreover, Clofibric acid inhibits VEGF expression in tumor xenografts of ovarian cancer cell lines with a reduction in angiogenesis and decreased microvessel density in solid tumors $[58,59]$.

\section{CONCLUSIONS}

Taken together, findings on the effects of PPAR $\alpha$ ligands in inflammation and cancer, suggest that PPAR $\alpha$ activation may be beneficial against tumorigenesis through the inhibition of transcriptional activation of genes involved in inflammation and angiogenesis such as COX-2 and VEGF. Although COX-2 and VEGF are one of the many proinflammatory and proangiogenic factors that drive tumor growth and metastasis, targeting these proteins suffices to significantly impair tumor growth and angiogenesis. Inhibition of tumor inflammation and tumor angiogenesis by $\operatorname{PPAR} \alpha$ ligands might be responsible for their potential chemopreventive effects in a variety of experimental models of cancer.
However, it must be taken into account that many of the reported effects of PPAR $\alpha$ ligands on tumor progression have been obtained in vitro and await confirmation by additional basic and clinical research to ascertain whether they can be considered of pharmacological significance in vivo.

\section{ACKNOWLEDGMENTS}

The authors thank the financial support of Comunidad Autónoma de Madrid (S-SAL-0159-2006), Ministerio de Educación y Ciencia-FEDER (SAF 2004-05109, BFU200404157, and BFU2007-62659), European Commission (EICOSANOX integrated project LSH-CT-2004-005033; and MAIN network of excellence), and Laboratorios del Dr. ESTEVE S. A. We apologize that many valuable studies, especially original contributions, have not been cited due to space limitation.

\section{REFERENCES}

[1] J. Berger and D. E. Moller, "The mechanisms of action of PPARs," Annual Review of Medicine, vol. 53, pp. 409-435, 2002.

[2] J. C. Corton, S. P. Anderson, and A. Stauber, "Central role of peroxisome proliferator-activated receptors in the actions of peroxisome proliferators," Annual Review of Pharmacology and Toxicology, vol. 40, pp. 491-518, 2000.

[3] L. Michalik and W. Wahli, "Peroxisome proliferator-activated receptors: three isotypes for a multitude of functions," Current Opinion in Biotechnology, vol. 10, no. 6, pp. 564-570, 1999.

[4] K. Schoonjans, B. Staels, and J. Auwerx, "The peroxisome proliferator activated receptors (PPARs) and their effects on lipid metabolism and adipocyte differentiation," Biochimica et Biophysica Acta, vol. 1302, no. 2, pp. 93-109, 1996.

[5] W. Wahli, O. Braissant, and B. Desvergne, "Peroxisome proliferator activated receptors: transcriptional regulators of adipogenesis, lipid metabolism and more," Chemistry and Biology, vol. 2, no. 5, pp. 261-266, 1995.

[6] R. A. Daynes and D. C. Jones, "Emerging roles of PPARs in inflammation and immunity," Nature Reviews Immunology, vol. 2, no. 10, pp. 748-759, 2002.

[7] L. Gelman, J.-C. Fruchart, and J. Auwerx, "An update on the mechanisms of action of the peroxisome proliferatoractivated receptors (PPARs) and their roles in inflammation and cancer," Cellular and Molecular Life Sciences, vol. 55, no. 6-7, pp. 932-943, 1999.

[8] L. Michalik, B. Desvergne, and W. Wahli, "Peroxisomeproliferator-activated receptors and cancers: complex stories," Nature Reviews Cancer, vol. 4, no. 1, pp. 61-70, 2004.

[9] J.-C. Fruchart, P. Duriez, and B. Staels, "Peroxisome proliferator-activated receptor-alpha activators regulate genes governing lipoprotein metabolism, vascular inflammation and atherosclerosis," Current Opinion in Lipidology, vol. 10, no. 3, pp. 245-257, 1999.

[10] I. Issemann and S. Green, "Activation of a member of the steroid hormone receptor superfamily by peroxisome proliferators," Nature, vol. 347, no. 6294, pp. 645-650, 1990.

[11] D. Auboeuf, J. Rieusset, L. Fajas, et al., "Tissue distribution and quantification of the expression of mRNAs of peroxisome proliferator-activated receptors and liver $\mathrm{X}$ receptor$\alpha$ in humans: no alteration in adipose tissue of obese and 
NIDDM patients," Diabetes, vol. 46, no. 8, pp. 1319-1327, 1997.

[12] I. Inoue, K. Shino, S. Noji, T. Awata, and S. Katayama, "Expression of peroxisome proliferator-activated receptor $\alpha$ $(\operatorname{PPAR} \alpha)$ in primary cultures of human vascular endothelial cells," Biochemical and Biophysical Research Communications, vol. 246, no. 2, pp. 370-374, 1998.

[13] T. C. Leone, C. J. Weinheimer, and D. P. Kelly, "A critical role for the peroxisome proliferator-activated receptor $\alpha(\operatorname{PPAR} \alpha)$ in the cellular fasting response: the PPAR $\alpha$-null mouse as a model of fatty acid oxidation disorders," Proceedings of the National Academy of Sciences of the United States of America, vol. 96, no. 13, pp. 7473-7478, 1999.

[14] T. M. Willson, P. J. Brown, D. D. Sternbach, and B. R. Henke, "The PPARs: from orphan receptors to drug discovery," Journal of Medicinal Chemistry, vol. 43, no. 4, pp. 527-550, 2000.

[15] J. M. Lehmann, J. M. Lenhard, B. B. Oliver, G. M. Ringold, and S. A. Kliewer, "Peroxisome proliferator-activated receptors $\alpha$ and $\gamma$ are activated by indomethacin and other nonsteroidal anti-inflammatory drugs," The Journal of Biological Chemistry, vol. 272, no. 6, pp. 3406-3410, 1997.

[16] H. E. Xu, M. H. Lambert, V. G. Montana, et al., "Molecular recognition of fatty acids by peroxisome proliferatoractivated receptors," Molecular Cell, vol. 3, no. 3, pp. 397-403, 1999.

[17] B. M. Forman, J. Chen, and R. M. Evans, "Hypolipidemic drugs, polyunsaturated fatty acids, and eicosanoids are ligands for peroxisome proliferator-activated receptors $\alpha$ and $\delta$," Proceedings of the National Academy of Sciences of the United States of America, vol. 94, no. 9, pp. 4312-4317, 1997.

[18] S. A. Kliewer, S. S. Sundseth, S. A. Jones, et al., "Fatty acids and eicosanoids regulate gene expression through direct interactions with peroxisome proliferator-activated receptors $\alpha$ and $\gamma$," Proceedings of the National Academy of Sciences of the United States of America, vol. 94, no. 9, pp. 4318-4323, 1997.

[19] K. Yu, W. Bayona, C. B. Kallen, et al., "Differential activation of peroxisome proliferator-activated receptors by eicosanoids," The Journal of Biological Chemistry, vol. 270, no. 41, pp. 23975-23983, 1995.

[20] L. A. Moraes, L. Piqueras, and D. Bishop-Bailey, "Peroxisome proliferator-activated receptors and inflammation," Pharmacology and Therapeutics, vol. 110, no. 3, pp. 371-385, 2006.

[21] P. R. Devchand, H. Keller, J. M. Peters, M. Vazquez, F. J. Gonzalez, and W. Wahli, "The PPAR $\alpha$-leukotriene B4 pathway to inflammation control," Nature, vol. 384, no. 6604, pp. 39-43, 1996.

[22] P. C. Calder, "n-3 polyunsaturated fatty acids, inflammation, and inflammatory diseases," American Journal of Clinical Nutrition, vol. 83, no. 6, pp. 1505S-1519S, 2006.

[23] P. C. Calder, "Polyunsaturated fatty acids and inflammation," Prostaglandins Leukotrienes and Essential Fatty Acids, vol. 75, no. 3, pp. 197-202, 2006.

[24] A. Madej, B. Okopien, J. Kowalski, et al., "Effects of fenofibrate on plasma cytokine concentrations in patients with atherosclerosis and hyperlipoproteinemia IIb," International Journal of Clinical Pharmacology and Therapeutics, vol. 36, no. 6, pp. 345-349, 1998.

[25] B. Staels, W. Koenig, A. Habib, et al., "Activation of human aortic smooth-muscle cells is inhibited by PPAR $\alpha$ but not by PPAR $\gamma$ activators," Nature, vol. 393, no. 6687, pp. 790-793, 1998.

[26] N. Marx, G. K. Sukhova, T. Collins, P. Libby, and J. Plutzky, "PPAR $\alpha$ activators inhibit cytokine-induced vascular cell adhesion molecule-1 expression in human endothelial cells," Circulation, vol. 99, no. 24, pp. 3125-3131, 1999.

[27] M. Meissner, M. Stein, C. Urbich, et al., "PPAR $\alpha$ activators inhibit vascular endothelial growth factor receptor-2 expression by repressing Sp1-dependent DNA binding and transactivation," Circulation Research, vol. 94, no. 3, pp. 324332, 2004.

[28] N. Marx, B. Kehrle, K. Kohlhammer, et al., "PPAR activators as antiinflammatory mediators in human $\mathrm{T}$ lymphocytes: implications for atherosclerosis and transplantationassociated arteriosclerosis," Circulation Research, vol. 90, no. 6, pp. 703-710, 2002.

[29] P. Delerive, K. De Bosscher, S. Besnard, et al., "Peroxisome proliferator-activated receptor $\alpha$ negatively regulates the vascular inflammatory gene response by negative cross-talk with transcription factors NF- $\kappa \mathrm{B}$ and AP-1," The Journal of Biological Chemistry, vol. 274, no. 45, pp. 32048-32054, 1999.

[30] R. Grau, C. Punzón, M. Fresno, and M. A. Iñiguez, "Peroxisome-proliferator-activated receptor $\alpha$ agonists inhibit cyclo-oxygenase 2 and vascular endothelial growth factor transcriptional activation in human colorectal carcinoma cells via inhibition of activator protein-1," Biochemical Journal, vol. 395, no. 1, pp. 81-88, 2006.

[31] A. Mouthiers, A. Baillet, C. Deloménie, D. Porquet, and N. Mejdoubi-Charef, "Peroxime proliferator-activated receptor $\alpha$ physically interacts with CCAAT/enhancer binding protein $(\mathrm{C} / \mathrm{EBP} \beta)$ to inhibit $\mathrm{C} / \mathrm{EBP} \beta$-responsive $\alpha 1$-acid glycoprotein gene expression," Molecular Endocrinology, vol. 19, no. 5, pp. 1135-1146, 2005.

[32] P. Gervois, N. Vu-Dac, R. Kleemann, et al., "Negative regulation of human fibrinogen gene expression by peroxisome proliferator-activated receptor $\alpha$ agonists via inhibition of CCAAT box/enhancer-binding protein $\beta$," The Journal of Biological Chemistry, vol. 276, no. 36, pp. 33471-33477, 2001.

[33] J. M. Shipley and D. J. Waxman, "Down-regulation of STAT5b transcriptional activity by ligand-activated peroxisome proliferator-activated receptor (PPAR) $\alpha$ and PPAR $\gamma$," Molecular Pharmacology, vol. 64, no. 2, pp. 355-364, 2003.

[34] P. Delerive, F. Martin-Nizard, G. Chinetti, et al., "Peroxisome proliferator-activated receptor activators inhibit thrombin- induced endothelin-1 production in human vascular endothelial cells by inhibiting the activator protein-1 signaling pathway," Circulation Research, vol. 85, no. 5, pp. 394-402, 1999.

[35] P. Desreumaux, L. Dubuquoy, S. Nutten, et al., "Attenuation of colon inflammation through activators of the retinoid $\mathrm{X}$ receptor (RXR)/peroxisome proliferator-activated receptor $\gamma$ (PPAR $\gamma$ ) heterodimer: a basis for new therapeutic strategies," Journal of Experimental Medicine, vol. 193, no. 7, pp. 827838, 2001.

[36] Y. Irukayama-Tomobe, T. Miyauchi, S. Sakai, et al., "Endothelin-1-induced cardiac hyperthrophy is inhibited by activation of peroxisome proliferator-activated receptor- $\alpha$ partly via blockade of c-Jun $\mathrm{NH}_{2}$-terminal kinase pathway," Circulation, vol. 109, no. 7, pp. 904-910, 2004.

[37] J. M. Peters, C. Cheung, and F. J. Gonzalez, "Peroxisome proliferator-activated receptor- $\alpha$ and liver cancer: where do we stand?" Journal of Molecular Medicine, vol. 83, no. 10, pp. 774-785, 2005.

[38] J. K. Reddy, D. L. Azarnoff, and C. E. Hignite, "Hypolipidaemic hepatic peroxisome proliferators form a novel class of chemical carcinogens," Nature, vol. 283, no. 5745, pp. 397$398,1980$. 
[39] S. S. Lee, T. Pineau, J. Drago, et al., "Targeted disruption of the $\alpha$ isoform of the peroxisome proliferator-activated receptor gene in mice results in abolishment of the pleiotropic effects of peroxisome proliferators," Molecular and Cellular Biology, vol. 15, no. 6, pp. 3012-3022, 1995.

[40] M. H. Frick, O. Elo, K. Haapa, et al., "Helsinki Heart Study: primary-prevention trial with gemfibrozil in middle-aged men with dyslipidemia. Safety of treatment, changes in risk factors, and incidence of coronary heart disease," The New England Journal of Medicine, vol. 317, no. 20, pp. 1237-1245, 1987.

[41] P. Gariot, E. Barrat, L. Mejean, J. P. Pointel, P. Drouin, and G. Debry, "Fenofibrate and human liver. Lack of proliferation of peroxisomes," Archives of Toxicology, vol. 53, no. 2, pp. 151$163,1983$.

[42] J. Ashby, A. Brady, C. R. Elcombe, et al., "Mechanisticallybased human hazard assessment of peroxisome proliferatorinduced hepatocarcinogenesis," Human and Experimental Toxicology, vol. 13, supplement 2, pp. S1-S117, 1994.

[43] S. Chevalier and R. A. Roberts, "Perturbation of rodent hepatocyte growth control by nongenotoxic hepatocarcinogens: mechanisms and lack of relevance for human health," Oncology Reports, vol. 5, no. 6, pp. 1319-1327, 1998.

[44] F. J. Gonzalez and Y. M. Shah, "PPAR $\alpha$ : mechanism of species differences and hepatocarcinogenesis of peroxisome proliferators," Toxicology, vol. 246, no. 1, pp. 2-8, 2008.

[45] J. W. Lawrence, Y. Li, S. Chen, et al., "Differential gene regulation in human versus rodent hepatocytes by peroxisome proliferator-activated receptor (PPAR) $\alpha$. PPAR $\alpha$ fails to induce peroxisome proliferation-associated genes in human cells independently of the level of receptor expression," The Journal of Biological Chemistry, vol. 276, no. 34, pp. 3152131527, 2001.

[46] C. N. A. Palmer, M.-H. Hsu, K. J. Griffin, J. L. Raucy, and E. F. Johnson, "Peroxisome proliferator activated receptor- $\alpha$ expression in human liver," Molecular Pharmacology, vol. 53, no. 1, pp. 14-22, 1998.

[47] G. P. Collett, A. M. Betts, M. I. Johnson, et al., "Peroxisome proliferator-activated receptor $\alpha$ is an androgen-responsive gene in human prostate and is highly expressed in prostatic adenocarcinoma," Clinical Cancer Research, vol. 6, no. 8, pp. 3241-3248, 2000.

[48] K. M. Suchanek, F. J. May, J. A. Robinson, et al., "Peroxisome proliferator-activated receptor $\alpha$ in the human breast cancer cell lines MCF-7 and MDA-MB-231," Molecular Carcinogenesis, vol. 34, no. 4, pp. 165-171, 2002.

[49] D. Panigrahy, A. Kaipainen, S. Huang, et al., "PPAR $\alpha$ agonist fenofibrate suppresses tumor growth through direct and indirect angiogenesis inhibition," Proceedings of the National Academy of Sciences of the United States of America, vol. 105, no. 3, pp. 985-990, 2008.

[50] L. Jackson, W. Wahli, L. Michalik, et al., "Potential role for peroxisome proliferator activated receptor (PPAR) in preventing colon cancer," Gut, vol. 52, no. 9, pp. 1317-1322, 2003.

[51] Y. Segawa, R. Yoshimura, T. Hase, et al., "Expression of peroxisome proliferator-activated receptor (PPAR) in human prostate cancer," The Prostate, vol. 51, no. 2, pp. 108-116, 2002.

[52] T. Hase, R. Yoshimura, M. Mitsuhashi, et al., "Expression of peroxisome proliferator-activated receptors in human testicular cancer and growth inhibition by its agonists," Urology, vol. 60, no. 3, pp. 542-547, 2002.
[53] R. Yoshimura, M. Matsuyama, Y. Segawa, et al., "Expression of peroxisome proliferator-activated receptors (PPARs) in human urinary bladder carcinoma and growth inhibition by its agonists," International Journal of Cancer, vol. 104, no. 5, pp. 597-602, 2003.

[54] K. Urbanska, P. Pannizzo, M. Grabacka, et al., "Activation of PPAR $\alpha$ inhibits IGF-I-mediated growth and survival responses in medulloblastoma cell lines," International Journal of Cancer, vol. 123, no. 5, pp. 1015-1024, 2008.

[55] G. Muzio, M. Maggiora, A. Trombetta, et al., "Mechanisms involved in growth inhibition induced by clofibrate in hepatoma cells," Toxicology, vol. 187, no. 2-3, pp. 149-159, 2003.

[56] M. Grabacka, P. M. Plonka, K. Urbanska, and K. Reiss, "Peroxisome proliferator-activated receptor $\alpha$ activation decreases metastatic potential of melanoma cells in vitro via down-regulation of Akt," Clinical Cancer Research, vol. 12, no. 10, pp. 3028-3036, 2006.

[57] S. A. Saidi, C. M. Holland, D. S. Charnock-Jones, and S. K. Smith, "In vitro and in vivo effects of the PPAR-alpha agonists fenofibrate and retinoic acid in endometrial cancer," Molecular Cancer, vol. 5, article 13, pp. 1-14, 2006.

[58] T. Shigeto, Y. Yokoyama, B. Xin, and H. Mizunuma, "Peroxisome proliferator-activated receptor $\alpha$ and $\gamma$ ligands inhibit the growth of human ovarian cancer," Oncology Reports, vol. 18, no. 4, pp. 833-840, 2007.

[59] Y. Yokoyama, B. Xin, T. Shigeto, et al., "Clofibric acid, a peroxisome proliferator-activated receptor $\alpha$ ligand, inhibits growth of human ovarian cancer," Molecular Cancer Therapeutics, vol. 6, no. 4, pp. 1379-1386, 2007.

[60] T. Tanaka, H. Kohno, S. Yoshitani, et al., "Ligands for peroxisome proliferator-activated receptors $\alpha$ and $\gamma$ inhibit chemically induced colitis and formation of aberrant crypt foci in rats," Cancer Research, vol. 61, no. 6, pp. 2424-2428, 2001.

[61] M. Maggiora, M. Bologna, M. P. Cerù, et al., "An overview of the effect of linoleic and conjugated-linoleic acids on the growth of several human tumor cell lines," International Journal of Cancer, vol. 112, no. 6, pp. 909-919, 2004.

[62] P. Thuillier, G. J. Anchiraico, K. P. Nickel, et al., "Activators of peroxisome proliferator-activated receptor- $\alpha$ partially inhibit mouse skin tumor promotion," Molecular Carcinogenesis, vol. 29, no. 3, pp. 134-142, 2000.

[63] M. Grabacka, W. Placha, P. M. Plonka, et al., "Inhibition of melanoma metastases by fenofibrate," Archives of Dermatological Research, vol. 296, no. 2, pp. 54-58, 2004.

[64] S. Goetze, F. Eilers, A. Bungenstock, et al., "PPAR activators inhibit endothelial cell migration by targeting Akt," Biochemical and Biophysical Research Communications, vol. 293, no. 5, pp. 1431-1437, 2002.

[65] J. Varet, L. Vincent, P. Mirshahi, et al., "Fenofibrate inhibits angiogenesis in vitro and in vivo," Cellular and Molecular Life Sciences, vol. 60, no. 4, pp. 810-819, 2003.

[66] A. Pozzi, M. R. Ibanez, A. E. Gatica, et al., "Peroxisomal proliferator-activated receptor- $\alpha$-dependent inhibition of endothelial cell proliferation and tumorigenesis," The Journal of Biological Chemistry, vol. 282, no. 24, pp. 17685-17695, 2007.

[67] A. Kaipainen, M. W. Kieran, S. Huang, et al., "PPAR $\alpha$ deficiency in inflammatory cells suppresses tumor growth," PLoS ONE, vol. 2, no. 2, p. e260, 2007.

[68] K. E. de Visser, A. Eichten, and L. M. Coussens, "Paradoxical roles of the immune system during cancer development," Nature Reviews Cancer, vol. 6, no. 1, pp. 24-37, 2006. 
[69] R. J. Prestwich, F. Errington, P. Hatfield, et al., "The immune system-is it relevant to cancer development, progression and treatment?" Clinical Oncology, vol. 20, no. 2, pp. 101$112,2008$.

[70] L. M. Coussens and Z. Werb, "Inflammation and cancer," Nature, vol. 420, no. 6917, pp. 860-867, 2002.

[71] A. Mantovani, P. Romero, A. K. Palucka, and F. M. Marincola, "Tumour immunity: effector response to tumour and role of the microenvironment," The Lancet, vol. 371, no. 9614, pp. 771-783, 2008.

[72] B. B. Aggarwal, S. Shishodia, S. K. Sandur, M. K. Pandey, and G. Sethi, "Inflammation and cancer: how hot is the link?" Biochemical Pharmacology, vol. 72, no. 11, pp. 1605-1621, 2006.

[73] S. J. Shiff, P. Shivaprasad, and D. L. Santini, "Cyclooxygenase inhibitors: drugs for cancer prevention," Current Opinion in Pharmacology, vol. 3, no. 4, pp. 352-361, 2003.

[74] M. J. Thun, S. J. Henley, and C. Patrono, "Nonsteroidal anti-inflammatory drugs as anticancer agents: mechanistic, pharmacologic, and clinical issues," Journal of the National Cancer Institute, vol. 94, no. 4, pp. 252-266, 2002.

[75] Y. Q. Chen, I. J. Edwards, S. J. Kridel, T. Thornburg, and I. M. Berquin, "Dietary fat-gene interactions in cancer," Cancer and Metastasis Reviews, vol. 26, no. 3-4, pp. 535-551, 2007.

[76] E. Escrich, R. Moral, L. Grau, I. Costa, and M. Solanas, "Molecular mechanisms of the effects of olive oil and other dietary lipids on cancer," Molecular Nutrition and Food Research, vol. 51, no. 10, pp. 1279-1292, 2007.

[77] I. Morita, "Distinct functions of COX-1 and COX-2," Prostaglandins \& Other Lipid Mediators, vol. 68-69, pp. 165175, 2002.

[78] W. L. Smith, D. L. DeWitt, and R. M. Garavito, "Cyclooxygenases: structural, cellular, and molecular biology," Annual Review of Biochemistry, vol. 69, pp. 145-182, 2000.

[79] T. Tanabe and N. Tohnai, "Cyclooxygenase isozymes and their gene structures and expression," Prostaglandins \& Other Lipid Mediators, vol. 68-69, pp. 95-114, 2002.

[80] D. L. Simmons, R. M. Botting, and T. Hla, "Cyclooxygenase isozymes: the biology of prostaglandin synthesis and inhibition," Pharmacological Reviews, vol. 56, no. 3, pp. 387-437, 2004.

[81] G. Dannhardt and W. Kiefer, "Cyclooxygenase inhibitorscurrent status and future prospects," European Journal of Medicinal Chemistry, vol. 36, no. 2, pp. 109-126, 2001.

[82] L. J. Marnett, "Recent developments in cyclooxygenase inhibition," Prostaglandins \& Other Lipid Mediators, vol. 6869, pp. 153-164, 2002.

[83] K. Subbaramaiah and A. J. Dannenberg, "Cyclooxygenase 2: a molecular target for cancer prevention and treatment," Trends in Pharmacological Sciences, vol. 24, no. 2, pp. 96-102, 2003.

[84] C. E. Eberhart, R. J. Coffey, A. Radhika, F. M. Giardiello, S. Ferrenbach, and R. N. Dubois, "Up-regulation of cyclooxygenase 2 gene expression in human colorectal adenomas and adenocarcinomas," Gastroenterology, vol. 107, no. 4, pp. 1183-1188, 1994.

[85] L. J. Marnett and R. N. DuBois, "COX-2: a target for colon cancer prevention," Annual Review of Pharmacology and Toxicology, vol. 42, pp. 55-80, 2002.

[86] G. Huls, J. J. Koornstra, and J. H. Kleibeuker, "Non-steroidal anti-inflammatory drugs and molecular carcinogenesis of colorectal carcinomas," The Lancet, vol. 362, no. 9379, pp. 230-232, 2003.
[87] R. A. Gupta and R. N. DuBois, "Colorectal cancer prevention and treatment by inhibition of cyclooxygenase-2," Nature Reviews Cancer, vol. 1, no. 1, pp. 11-21, 2001.

[88] T. Kawamori, C. V. Rao, K. Seibert, and B. S. Reddy, "Chemopreventive activity of celecoxib, a specific cyclooxygenase-2 inhibitor, against colon carcinogenesis," Cancer Research, vol. 58, no. 3, pp. 409-412, 1998.

[89] S. Gately, "The contributions of cyclooxygenase-2 to tumor angiogenesis," Cancer and Metastasis Reviews, vol. 19, no. 12, pp. 19-27, 2000.

[90] M. A. Iñiguez, A. Rodríguez, O. V. Volpert, M. Fresno, and J. M. Redondo, "Cyclooxygenase-2: a therapeutic target in angiogenesis," Trends in Molecular Medicine, vol. 9, no. 2, pp. 73-78, 2003.

[91] I. Tegeder, J. Pfeilschifter, and G. Geisslinger, "Cyclooxygenase-independent actions of cyclooxygenase inhibitors," The FASEB Journal, vol. 15, no. 12, pp. 20572072, 2001.

[92] M. S. Jaradat, B. Wongsud, S. Phornchirasilp, et al., "Activation of peroxisome proliferator-activated receptor isoforms and inhibition of prostaglandin $\mathrm{H}_{2}$ synthases by ibuprofen, naproxen, and indomethacin," Biochemical Pharmacology, vol. 62, no. 12, pp. 1587-1595, 2001.

[93] J. M. Lehmann, J. M. Lenhard, B. B. Oliver, G. M. Ringold, and S. A. Kliewer, "Peroxisome proliferator-activated receptors $\alpha$ and $\gamma$ are activated by indomethacin and other nonsteroidal anti-inflammatory drugs," The Journal of Biological Chemistry, vol. 272, no. 6, pp. 3406-3410, 1997.

[94] C. K. Combs, P. Bates, J. C. Karlo, and G. E. Landreth, "Regulation of $\beta$-amyloid stimulated proinflammatory responses by peroxisome proliferator-activated receptor $\alpha$," Neurochemistry International, vol. 39, no. 5-6, pp. 449-457, 2001.

[95] J. Yu, E. Ip, A. Dela Peña, et al., "COX-2 induction in mice with experimental nutritional steatohepatitis: role as proinflammatory mediator," Hepatology, vol. 43, no. 4, pp. 826836, 2006.

[96] A. D. Blann, F. M. Belgore, J. Constans, C. Conri, and G. Y. H. Lip, "Plasma vascular endothelial growth factor and its receptor Flt-1 in patients with hyperlipidemia and atherosclerosis and the effects of fluvastatin or fenofibrate," American Journal of Cardiology, vol. 87, no. 10, pp. 1160 1163, 2001.

[97] D. Hanahan and J. Folkman, "Patterns and emerging mechanisms of the angiogenic switch during tumorigenesis," Cell, vol. 86, no. 3, pp. 353-364, 1996.

[98] J. Folkman, "Angiogenesis in cancer, vascular, rheumatoid and other disease," Nature Medicine, vol. 1, no. 1, pp. 27-31, 1995.

[99] P. Carmeliet and R. K. Jain, "Angiogenesis in cancer and other diseases," Nature, vol. 407, no. 6801, pp. 249-257, 2000.

[100] G. Bergers and L. E. Benjamin, "Tumorigenesis and the angiogenic switch," Nature Reviews Cancer, vol. 3, no. 6, pp. 401-410, 2003.

[101] D. Liao and R. S. Johnson, "Hypoxia: a key regulator of angiogenesis in cancer," Cancer and Metastasis Reviews, vol. 26, no. 2, pp. 281-290, 2007.

[102] M. M. Hickey and M. C. Simon, "Regulation of angiogenesis by hypoxia and hypoxia-inducible factors," Current Topics in Developmental Biology, vol. 76, pp. 217-257, 2006.

[103] A. Weidemann and R. S. Johnson, "Biology of HIF-1 $\alpha$," Cell Death and Differentiation, vol. 15, no. 4, pp. 621-627, 2008. 
[104] A. Kaidi, D. Qualtrough, A. C. Williams, and C. Paraskeva, "Direct transcriptional up-regulation of cyclooxygenase-2 by hypoxia-inducible factor (HIF)-1 promotes colorectal tumor cell survival and enhances HIF-1 transcriptional activity during hypoxia," Cancer Research, vol. 66, no. 13, pp. 66836691, 2006.

[105] N. Simiantonaki, C. Jayasinghe, R. Michel-Schmidt, K. Peters, M. I. Hermanns, and C. J. Kirkpatrick, "Hypoxiainduced epithelial VEGF-C/VEGFR-3 upregulation in carcinoma cell lines," International Journal of Oncology, vol. 32, no. 3, pp. 585-592, 2008.

[106] P. Pichiule, J. C. Chavez, and J. C. LaManna, "Hypoxic regulation of angiopoietin-2 expression in endothelial cells," The Journal of Biological Chemistry, vol. 279, no. 13, pp. 12171-12180, 2004.

[107] E. B. Rankin and A. J. Giaccia, "The role of hypoxia-inducible factors in tumorigenesis," Cell Death and Differentiation, vol. 15, no. 4, pp. 678-685, 2008.

[108] N. Ferrara, "VEGF: an update on biological and therapeutic aspects," Current Opinion in Biotechnology, vol. 11, no. 6, pp. 617-624, 2000.

[109] M. J. Cross and L. Claesson-Welsh, "FGF and VEGF function in angiogenesis: signalling pathways, biological responses and therapeutic inhibition," Trends in Pharmacological Sciences, vol. 22, no. 4, pp. 201-207, 2001.

[110] Q. T. Ho and C. J. Kuo, "Vascular endothelial growth factor: biology and therapeutic applications," International Journal of Biochemistry and Cell Biology, vol. 39, no. 7-8, pp. 13491357, 2007.

[111] N. Ferrara, H.-P. Gerber, and J. LeCouter, "The biology of VEGF and its receptors," Nature Medicine, vol. 9, no. 6, pp. 669-676, 2003.

[112] M. Shibuya and L. Claesson-Welsh, "Signal transduction by VEGF receptors in regulation of angiogenesis and lymphangiogenesis," Experimental Cell Research, vol. 312, no. 5, pp. 549-560, 2006.

[113] M. Shibuya, N. Ito, and L. Claesson-Welsh, "Structure and function of vascular endothelial growth factor receptor-1 and -2," Current Topics in Microbiology and Immunology, vol. 237, pp. 59-83, 1999.

[114] A. W. Griffioen and G. Molema, "Angiogenesis: potentials for pharmacologic intervention in the treatment of cancer, cardiovascular diseases, and chronic inflammation," Pharmacological Reviews, vol. 52, no. 2, pp. 237-268, 2000.

[115] T. Kasai, K. Miyauchi, T. Yokoyama, K. Aihara, and H. Daida, "Efficacy of peroxisome proliferative activated receptor (PPAR)- $\alpha$ ligands, fenofibrate, on intimal hyperplasia and constrictive remodeling after coronary angioplasty in porcine models," Atherosclerosis, vol. 188, no. 2, pp. 274-280, 2006. 


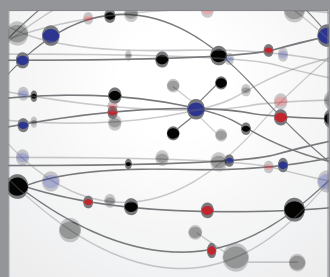

The Scientific World Journal
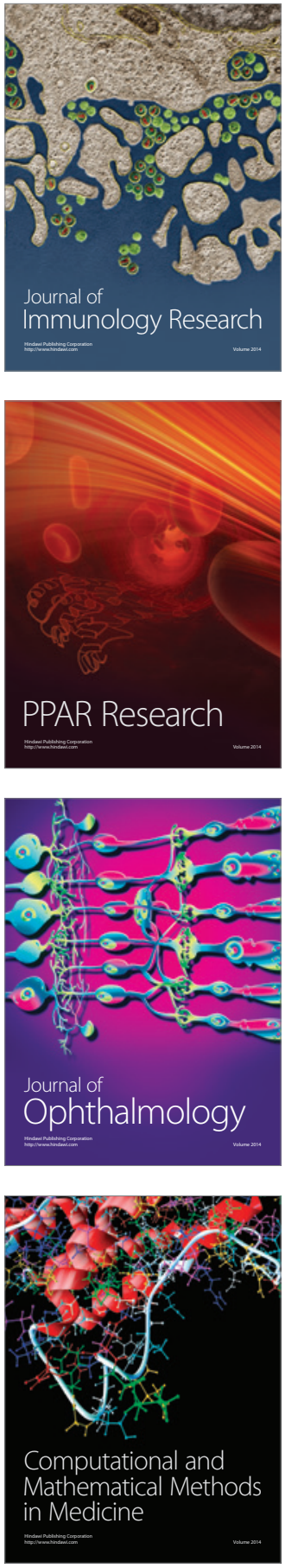

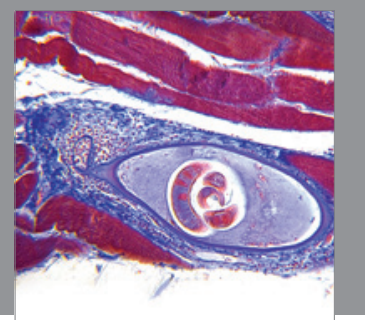

Gastroenterology

Research and Practice
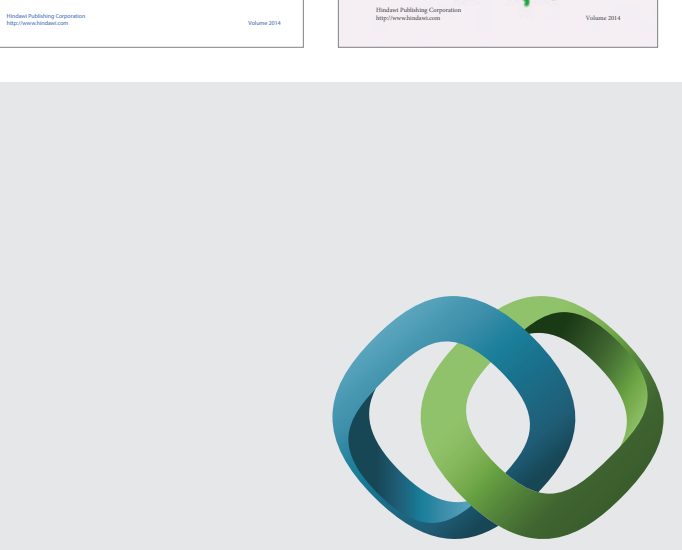

\section{Hindawi}

Submit your manuscripts at

http://www.hindawi.com
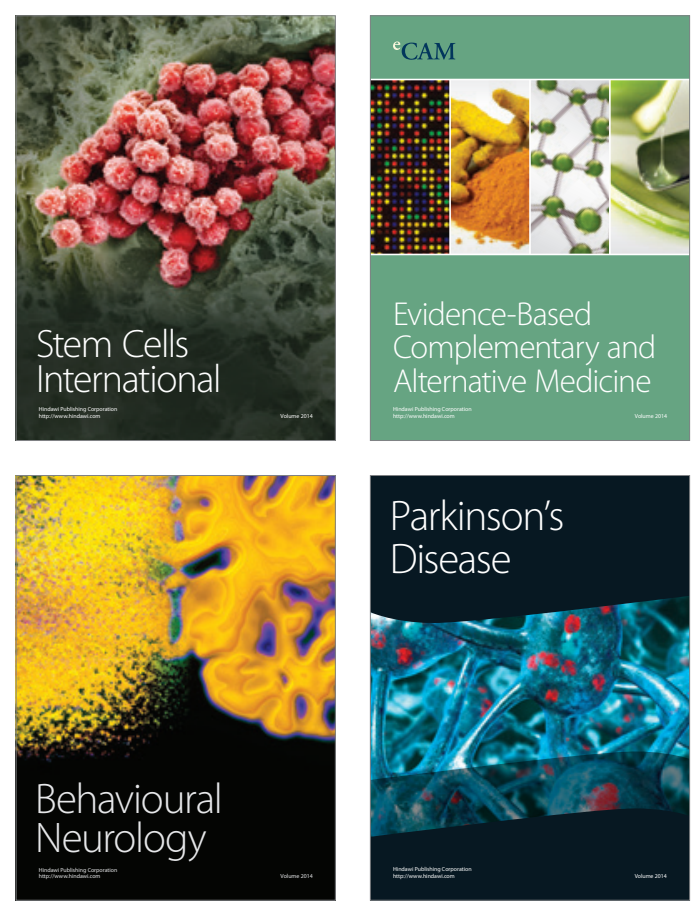

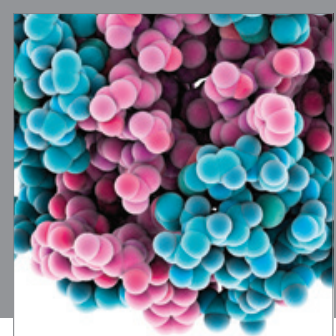

Journal of
Diabetes Research

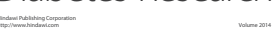

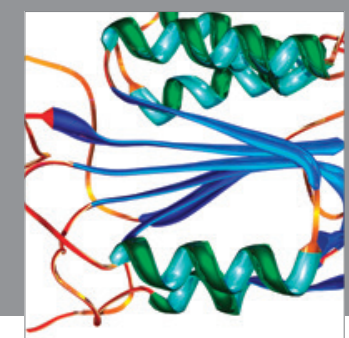

Disease Markers
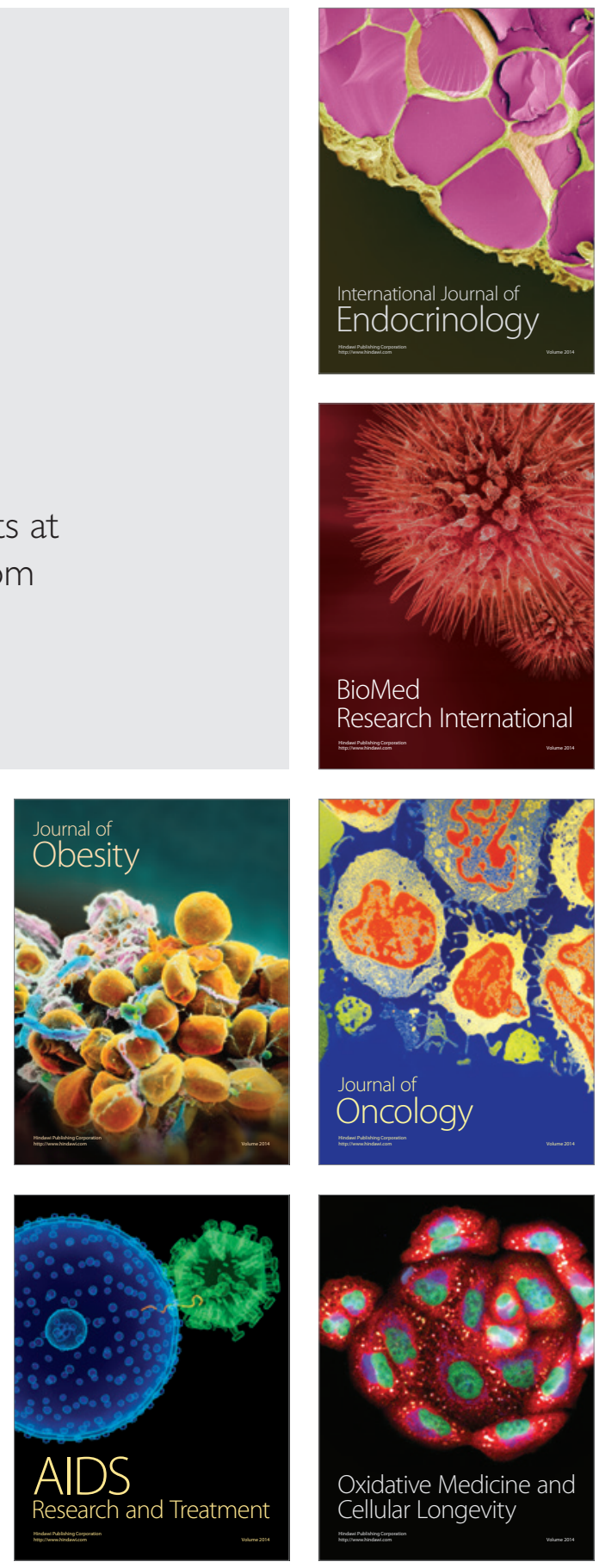